\title{
A novel HDAC1 inhibitor, CBUD-1001, exerts anticancer effects by modulating the apoptosis and EMT of colorectal cancer cells
}

\author{
SE LIM KIM ${ }^{1 *}$, MINH THANH LA ${ }^{2,3^{*}}$, MIN WOO SHIN ${ }^{1}$, SANG-WOOK KIM $^{1}$ and HEE-KWON KIM ${ }^{2,3}$ \\ ${ }^{1}$ Department of Internal Medicine, Research Institute of Clinical Medicine of Jeonbuk National University-Biomedical \\ Research Institute of Jeonbuk National University Hospital; ${ }^{2}$ Department of Nuclear Medicine, \\ Molecular Imaging and Therapeutic Medicine Research Center, Jeonbuk National University Medical School and Hospital; \\ ${ }^{3}$ Research Institute of Clinical Medicine of Jeonbuk National University-Biomedical Research Institute of \\ Jeonbuk National University Hospital, Jeonju, Jeonbuk 54907, Republic of Korea
}

Received February 10, 2020; Accepted July 16, 2020

DOI: $10.3892 /$ ijo. 2020.5109

\begin{abstract}
Colorectal cancer (CRC) is one of the most commonly diagnosed malignancies and is a leading cause of cancer-related mortality worldwide. Histone deacetylases (HDACs) are a class of enzymes responsible for the epigenetic regulation of gene expression. Some HDAC inhibitors have been shown to be efficient agents for cancer treatment. The aim of the present study was to discover a novel, potent HDAC inhibitor and demonstrate its anticancer effect and molecular mechanisms in CRC cells. A novel fluorinated aminophenyl-benzamide-based compound, CBUD-1001, was designed to specifically target HDAC1, and it was then synthesized and evaluated. CBUD-1001 exerted a potent inhibitory effect on HDAC enzyme activity and exhibited anticancer potency against CRC cell lines. Molecular docking analysis rationalized the high potency of CBUD-1001 by validating its conformation in the HDAC active site. Further investigation using CRC cells demonstrated that CBUD-1001 inhibited HDAC activity by hyper-acetylating histones $\mathrm{H} 3$ and $\mathrm{H} 4$, and it exerted an apoptotic effect by activating a
\end{abstract}

Correspondence to: Professor Hee-Kwon Kim, Department of Nuclear Medicine, Molecular Imaging and Therapeutic Medicine Research Center, Jeonbuk National University Medical School and Hospital, 20 Geonji-ro, Deokjin-gu, Jeonju, Jeonbuk 54907, Republic of Korea

E-mail: hkkim717@jbnu.ac.kr

Professor Sang-Wook Kim, Department of Internal Medicine, Research Institute of Clinical Medicine of Jeonbuk National University-Biomedical Research Institute of Jeonbuk National University Hospital, 20 Geonji-ro, Deokjin-gu, Jeonju, Jeonbuk 54907, Republic of Korea

E-mail: clickm@jbnu.ac.kr

*Contributed equally

Key words: colorectal cancer, histone deacetylases, histone deacetylase inhibitor, apoptosis, epithelial-mesenchymal transition mitochondrial-dependent pathway. Of note, it was found that CBUD-1001 attenuates the cell motility of CRC cells by downregulating the EMT signaling pathway. Thus, CBUD-1001 may prove to be a promising novel drug candidate for CRC therapy.

\section{Introduction}

Colorectal cancer (CRC) is the third most common malignancy and the fourth highest cause of cancer-related mortality, accounting for approximately 1.36 million new cases and 694,000 deaths worldwide in 2012 (1,2). Several risk factors are associated with the development of CRC, including familial history, inherited genetic mutations and food habits (3). A main cause of $\mathrm{CRC}$, epigenetic alteration, can drive the transformation from normal cells to cancer (4). Therefore, such alterations are commonly perceived to be good molecular targets for future CRC treatments.

Histone deacetylases (HDACs) are a family of crucial epigenetic enzymes that play an important role in the regulation of gene expression. The 18 isoforms of this family are classified into 4 groups: The zinc-dependent HDACs comprise class I (HDAC1, 2, 3 and 8), class II (HDAC4, 5, 6, 7, 9 and 10) and class IV (HDAC 11), and the NAD ${ }^{+}$-dependent HDACs which belong to class III (SIRT1-7) (5-7). HDAC1 and HDAC2, members of HDAC class I, are found in mammalian cell nuclei and are located in 3 major, stable, multiprotein co-repressor complexes: Sin3, nucleosome remodeling and deacetylation (NuRD) and co-repressor for element-1-silencing transcription factor (CoREST) $(8,9)$.

The effects of HDACs on cell behavior were recently demonstrated in several studies. HDAC1 and 2 antagonize tumor suppressor p53 in the regulation of the cyclin-dependent kinase (CDK) inhibitor p21, a key component in cell cycle control and apoptosis (10-12). The knockdown of HDAC1 and 2 induces the expression of CDK inhibitors, which leads to a cell cycle block in G1 and apoptotic cell death (13). Furthermore, the aberrant upregulation of HDAC $1 / 2$ is involved in the progression of various types of cancer. Therefore, the inhibition of HDAC1/2 has emerged as an effective anticancer treatment. 
In CRC cells, several studies have revealed that the upregulation pf $\mathrm{HDAC} 1 / 2$ found at the beginning of colon carcinogenesis is implicated in cell tumorigenicity via chromatin structure remodeling $(14,15)$. The epithelial-mesenchymal transition (EMT) process, which plays a role in the growth of several types of CRC, is involved in aberrant HDAC expression through the SNAIL transcription factors (16-18). In addition, a decline in HDAC1 and 2 is considered to inhibit the proliferation and induce the death of several CRC cell lines by activating specific tumor-suppressor genes $(19,20)$. Thus, the development of CRC-targeted HDAC inhibitors is potentially valuable in the search for new selective chemotherapy agents. Several types of HDAC inhibitors have recently been developed for the treatment of CRC (21-26). Hydroxamic acid-based HDAC inhibitors have been used in the treatment of CRC. For example, suberoylanilide hydroxamic acid (SAHA), approved by the FDA for the treatment of T-cell lymphoma, has been tested on solid tumors, including CRC $(27,28)$. However, unselective HDAC inhibition (SAHA inhibits approximately 11 isoforms of HDAC) could have undesirable side-effects $(29,30)$. Benzamide-type HDAC inhibitors also potentially inhibit several cancer cell lines $(26,31)$. The benzamide-type structure has a higher affinity to zinc ions than hydroxamate-type HDAC inhibitors, which produces highly selective class I HDAC inhibition and thereby significantly reduces the side-effects of HDAC inhibition (32). Several previous studies have modified benzamide-type HDAC inhibitors by adding an aryl group at the aniline to bind to the 14-A-long internal cavity, known to be where the acetate byproduct is released after enzymatic hydrolysis. The resulting increase in potency indicates that the modification produces benefits for benzamide-type HDAC inhibitors (33-35).

The present study wished to discover a novel, potent HDAC inhibitor that could serve as an antitumor agent via its benzamide moiety. From previous studies on benzamide-type HDAC inhibitors, it was expected that structural modification of the internal cavity and a cap group would enhance the binding potency of a benzamide-type HDAC inhibitor and improve its inhibition activity and antitumor activity (32-35). The present study reports the design and synthesis of a novel fluorinated aminophenyl-benzamide-based compound, CBUD-1001, along with biological evaluations of CBUD-1001 as a novel HDAC inhibitor with potent antitumor agent against CRC.

\section{Materials and methods}

HDAC inhibitory assay. The HDAC inhibition assay of CBUD-1001 was conducted by the Reaction Biology Corporation. CBUD-1001 was suspended in $10 \mathrm{mM}$ DMSO stock solution. The compound was tested in singlet 10-dose inhibitory concentration $\left(\mathrm{IC}_{50}\right)$ mode with 3-fold serial dilution starting at $1 \mu \mathrm{M}$ against HDAC1 and 2. A fluorogenic peptide from p53 residues 379-382 [RHKK(Ac)AMC] was used as the substrate for HDAC1 and 2. $\mathrm{IC}_{50}$ values were calculated using the GraphPad Prism 4 program based on a sigmoidal dose-response equation. The blank (DMSO) value was entered as a concentration of $1.00 \mathrm{E}^{-12}$ for curve fitting.

Molecular docking analysis. A docking model of CBUD-1001 was calculated on an Intel ${ }^{\circledR}$ Core $^{\mathrm{TM}}$ i7-8700 CPU @ 3.20 GHz
(12 CPUs), using Schrödinger Maestro 11.9 software (Schrödinger, LLC) and an HDAC model (4LY1) available on a protein data bank (36). A grid box was created with the following specifications: VdW radii of protein atoms scaled by 1.0; charged cut-off for polarity 0.25 ; receptor setup (nsite, $n x$, ny, nz, bsite $)=(125,19,19,19,1.0)$; Dockman after grid: (nx, ny, $n z)=(56,56,56)$. The inhibitory ability of the compound was expected to follow the calculated docking score. $2 \mathrm{D}$ and $3 \mathrm{D}$ images of the interactions were also recorded.

Cell lines and cell culture. Human CRC cell lines (HCT116 and DLD-1) were purchased from the American Type Culture Collection. The 3 human CRC cell lines were validated by short-tandem repeat (STR) DNA fingerprinting using the Promega PowerPlex 18D System and analyzed by GeneMapper Software 5 at Cosmo Genetech Korea. Human intestinal epithelial cells (IECs) were purchased from Lonza as a normal control. The CRC cells were cultured in RPMI-1640 medium supplemented with $10 \%$ heat-inactivated fetal bovine serum (FBS), 100 units of penicillin, and 100 units of streptomycin. Human IEC cells were cultured in $\mathrm{SmGM}^{\mathrm{TM}}-2$ medium (Lonza Group, Ltd.), containing various supplements and growth factors (insulin, hFGF-B, hEGF, FBS and gentamicin/amphotericin-B). All cells were maintained at $37^{\circ} \mathrm{C}$ in a humidified incubator with $5 \% \mathrm{CO}_{2} / 95 \%$ air.

Cell viability assay. The effects of CBUD-1001 on the proliferation of human IEC, HCT116 and DLD-1 cells were evaluated using 3-(4,5-dimethylthiazol-2-yl)-2,5-diphenyl tetrazolium bromide (MTT, Sigma-Aldrich; Merck KGaA), and cell viability was associated with the production of formazan. The cells were plated at a density of $1.0 \times 10^{4}$ cells per well in 96-well plates. Following treatment with $0,0.05$, $0.1,1,10,50,100$ and $200 \mu \mathrm{M}$ of CBUD-1001 for $24 \mathrm{~h}, 20 \mu \mathrm{l}$ of MTT $(5 \mathrm{mg} / \mathrm{ml})$ were added to each well. Following incubation for $4 \mathrm{~h}$ at $37^{\circ} \mathrm{C}$, the culture medium containing MTT was removed, and $200 \mu \mathrm{l}$ of DMSO were added. This was followed by shaking until the crystals were dissolved. Viable cells were detected by measuring the absorbance at $570 \mathrm{~nm}$ using a microplate reader (Molecular Devices, LLC). The $\mathrm{IC}_{50}$ value of CBUD-1001 was then calculated in comparison to the untreated controls.

Detection of cell apoptosis. Following treatment with 0,1 and $3 \mu \mathrm{M}$ of CBUD-1001 for $24 \mathrm{~h}$, cells were trypsinized, collected and washed with ice-cold PBS. The following steps were based on the manufacturer's instructions for the Annexin V-FITC/Propidium Iodide (PI) Apoptosis Detection kit (BD Biosciences). After staining the cells with $5 \mu \mathrm{l}$ of Annexin V-FITC and $5 \mu \mathrm{l}$ of PI for $15 \mathrm{~min}$ at room temperature in the dark, the fluorescence was measured on a BD LSR flow cytometer (BD Biosciences) and processed using Cell Quest software (BD Biosciences) for analysis. The apoptotic features of the cancer cells were assessed by DNA condensation using Hoechst 33258. The cells were treated with 1 and $3 \mu \mathrm{M}$ of CBUD-1001 for $24 \mathrm{~h}$ and then stained with Hoechst $33258(1 \mu \mathrm{g} / \mathrm{ml})$ at $37^{\circ} \mathrm{C}$ for $10 \mathrm{~min}$. Nuclear morphology was examined under a confocal laser scanning microscope (Carl Zeiss AG) to identify cells undergoing apoptosis. 
Colony formation assay. For the colony formation assay, cells $\left(1 \times 10^{2}\right.$ cells/well $)$ were seeded into a 6 -well plate and then treated with the 0,1 and $3 \mu \mathrm{M}$ of CBUD-1001 for $24 \mathrm{~h}$. The cells were then washed with cold $1 \mathrm{X}$ PBS, and fresh growth medium was added. Following 14 days of culture, the colonies were fixed with $3.8 \%$ formaldehyde for $20 \mathrm{~min}$ and stained with $0.1 \%$ crystal violet (Sigma-Aldrich; Merck KGaA) for $10 \mathrm{~min}$ at room temperature.

Protein extraction and western blot analysis. Cells were harvested by resolving them in RIPA buffer $(50 \mathrm{mM}$ Tris- $\mathrm{HCl}$, $150 \mathrm{mM} \mathrm{NaCl}, 1 \%$ Triton X-100, $1 \%$ sodium deoxycholate, $0.1 \%$ SDS, and protease inhibitors) with a strong vortex followed by centrifugation at $15,800 \mathrm{x} \mathrm{g}$ and $4^{\circ} \mathrm{C}$ for $30 \mathrm{~min}$. Following centrifugation, the supernatants were used as whole cell extracts. The protein concentration in the cell lysates was measured using a protein quantification kit from Bio-Rad Laboratories, Inc. A total of 50 or $30 \mu \mathrm{g}$ of protein per lane was loaded onto an SDS-polyacrylamide gel. Following transfer and blocking with $3 \%$ bovine serum albumin, the polyvinylidene difluoride membrane was probed with various antibodies [anti-Ac-histone H3 (1:1,000, sc-56616; Santa Cruz Biotechnology, Inc.), anti-Ac-histone H4 (1:1,000, sc-515319, Santa Cruz Biotechnology, Inc.), anti-caspase 8 (1:1,000, sc-73526, Santa Cruz Biotechnology, Inc.), anti-tBid (1:1,000, sc-34325, Santa Cruz Biotechnology, Inc.), anti-Bcl-2 (1:2,000, \#2872, Cell Signaling Technology, Inc.) anti-Bcl-xL (1:1,000, sc-8392, Santa Cruz Biotechnology, Inc.), anti-Bax (1:1,000, sc-7480, Santa Cruz Biotechnology, Inc.), anti-cytochrome $c(1: 1,000$, sc-13156, Santa Cruz Biotechnology, Inc.), anti-X-linked inhibitor of apoptosis protein (XIAP, 1:2,000, \#14334, Cell Signaling Technology, Inc.), anti-caspase 3 (1:1,000, sc-7148, Santa Cruz Biotechnology, Inc.), anti-poly(ADP-ribose) polymerase (PARP, sc-7150, 1:1,000, Santa Cruz Biotechnology, Inc.), anti-E-cadherin (1:2,000, \#3195, Cell Signaling Technology, Inc.), anti- $\beta$-catenin (1:2,000, \#9582, Cell Signaling Technology, Inc.), anti-vimentin (1:2,000, \#5741, Cell Signaling Technology, Inc.), anti-matrix metalloproteinase (MMP)2 (1:2,000, \#13132, Cell Signaling Technology, Inc.), anti-MMP9 (1:2,000, ab76003, Abcam), anti-SNAIL (1:2,000, ab180714, Abcam), anti-SLUG (1:2,000, ab27568, Abcam) and anti-actin (1:2,000, A2066, Sigma-Aldrich; Merck KGaA)] at $4^{\circ} \mathrm{C}$ for overnight. Membranes were incubated with horseradish peroxidase-conjugated secondary antibodies [anti-mouse IgG (1:1,000, sc-2005, Santa Cruz Biotechnology, Inc.), anti-rabbit IgG (1:1,000, sc-2004, Santa Cruz Biotechnology, Inc.) anti-goat IgG (1:1,000, sc-2354, Santacruz Biotechnology, Inc.)] for $1 \mathrm{~h}$ at room temperature. Antibody-to-antigen binding was detected using an Enhanced ECL Prime (GE Healthcare) and was captured and analyzed by a Las-3000 luminescent image analyzer (Fuji Film).

Measurement of HDAC concentration. A colorimetric HDAC activity assay kit was used to determine the in vitro HDAC concentration (BioVision, Inc.). The cells were plated at a density of $1.0 \times 10^{6}$ cells in a $10-\mathrm{cm}$ dish. Following treatment with CBUD-1001, total cell lysates were resolved using RIPA buffer. The assay was performed according to the manufacturer's protocol.
Mitochondrial transmembrane potential (MMP, $\Delta \psi m)$. The mitochondrial membrane was monitored using Rhodamine 123 fluorescent dye $(E x / E m=485$ nm/535 nm; Sigma-Aldrich; Merck $\mathrm{KGaA}$ ), a cell-permeable cationic dye that preferentially enters the mitochondria due to the highly negative $\Delta \psi \mathrm{m}$. The depolarization of the $\Delta \psi \mathrm{m}$ results in the loss of Rhodamine 123 from the mitochondria and a decrease in intracellular fluorescence. In brief, cells were incubated with 0,1 and $3 \mu \mathrm{M}$ of CBUD-1001 for $24 \mathrm{~h}$. The cells were then washed twice with PBS and incubated with Rhodamine 123 $(0.1 \mu \mathrm{g} / \mathrm{ml})$ at $37^{\circ} \mathrm{C}$ for $30 \mathrm{~min}$. The intensity of Rhodamine 123 staining was determined using a BD LSR flow cytometer (BD Biosciences).

Wound healing assay and morphological analysis. Cells $\left(1 \times 10^{5}\right)$ were seeded in $6-\mathrm{cm}$ culture plates and allowed to form a confluent monolayer. The monolayer was scraped with a P200 pipette tip to generate a wound $\sim 1 \mathrm{~mm}$ wide, and the cells were then treated with 0,1 and $3 \mu \mathrm{M}$ of CBUD-1001. Images of the wounds were captured at $0,48 \mathrm{~h}$, and the wound area was determined using an inverted microscope (Olympus IX71, Olympus Corporation). The ability of the cells to close the wound, as a measure of motility, was evaluated by determining the healed area. In addition, morphological alterations of the CRC cells were observed using an inverted microscope (Olympus IX71, Olympus Corporation).

Statistical analysis. For data analysis for the in vitro experiments, one-way ANOVA (for differences between multiple groups) assuming equality of variance with Tukey's multiple comparison test, were used. The data are presented as the means \pm SD of at least 3 independent experiments. All data were entered into Microsoft Excel 5.0, and GraphPad Prism 5.0 was used. A probability $(\mathrm{P})$-value $<0.05$ was considered to indicate a statistically significant difference.

\section{Results}

Synthesis and in vitro HDAC inhibitory assay of CBUD-1001. The synthesis of the novel HDAC inhibitor (CBUD-1001) used in the present study was achieved via 6 step reactions from 4-bromo-2-nitroaniline (Figs. 1, S1 and S2, and Data S1). The newly synthesized compound (CBUD-1001) was examined for its HDAC1, HDAC2 and HDAC3 inhibitory activity using a fluorogenic peptide from p53 residues 379-382 [RHKK(Ac)AMC] as the HDAC substrate. The $\mathrm{IC}_{50}$ values of CBUD-1001 exhibited nanomolar inhibition against HDAC1, and sub-micromolar inhibition against HDAC2 and HDAC3: $\mathrm{IC}_{50}=28.1 \mathrm{nM}$ against HDAC1, $\mathrm{IC}_{50}=158 \mathrm{nM}$ against HDAC2, and $\mathrm{IC}_{50}=404 \mathrm{nM}$ against HDAC 3 . For the positive control, the $\mathrm{IC}_{50}$ values of SAHA against HDAC1, HDAC2 and HDAC3 were 115, 162 and $181 \mathrm{nM}$. Thus, CBUD-1001 exhibited potent HDAC inhibitory activity (data not shown).

Docking analysis. To better understand the high HDAC inhibitory activity of CBUD-1001, it was docked into the active sites of HDAC using the Glide module of Schrödinger software with the Maestro interface. The docking analysis produced a docking score of $-13.283(\mathrm{kcal} / \mathrm{mol})$. Both the 


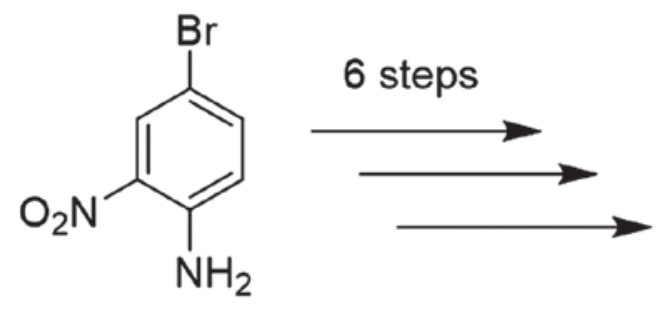<smiles>Nc1ccc(-c2cccs2)cc1NC(=O)c1ccc(CNC(=O)C2CCC(CF)CC2)cc1</smiles>

Figure 1. A novel HDAC inhibitor (CBUD-1001). The synthesis of HDAC inhibitor (CBUD-1001) from 4-bromo-2-nitroaniline was achieved via several step reactions (Boc-protection, the Suzuki cross-coupling reaction, hydrogenation, amide bond formation, and Gabriel synthesis, EDC coupling reaction and deprotection of the Boc group).
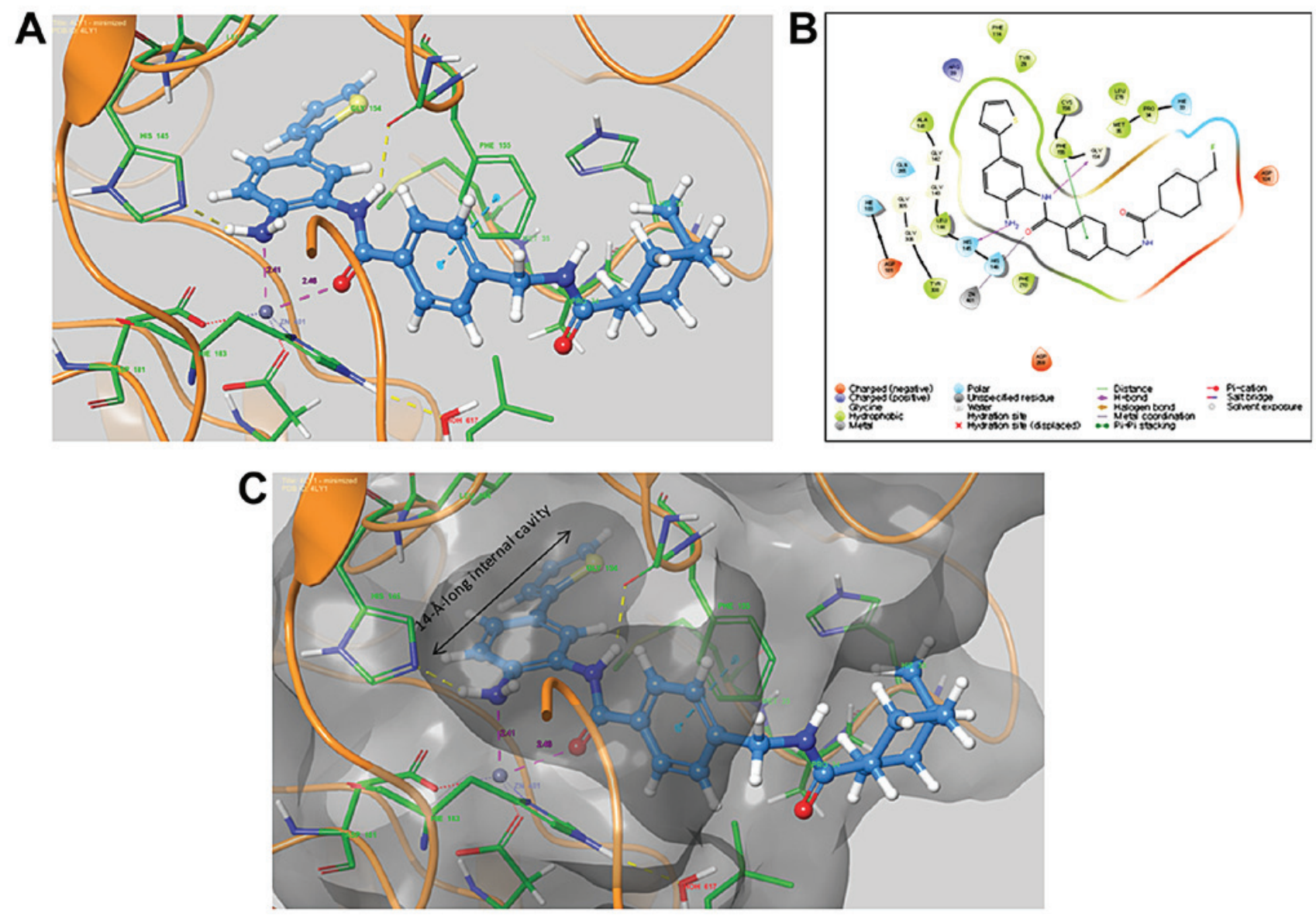

Figure 2. Predicted binding modes of CBUD-1001 on HDACs. (A) Interaction of CBUD-1001 with Zn-binding site of HDACs in 3D model (4LY1 model): H-Bond (yellow dashed line), metal coordination (pink dashed line) and $\pi-\pi$ stacking (blue dashed line). (B) Interaction of CBUD-1001 with binding pocket of HDACs in 2D model (4LY1 model). (C) CBUD-1001 fit with binding pocket of HDACs in 3D model (4LY1 model).

nitrogen in the ortho- $\mathrm{NH}_{2}$ group and the carbonyl group in the core structure were observed to chelate with Zn401 (Fig. 2). The ortho- $\mathrm{NH}_{2}$ group also interacted with His145, and the $\mathrm{NH}$ amide established a hydrogen bond with the $\mathrm{C}=\mathrm{O}$ on Gly154. There was a $\pi-\pi$ stacking interaction between the phenyl group of the linker and Phe155. The thiophenyl group was adequately located, with a $14-\AA$-long internal cavity. The presence of the thiophenyl group was deemed to significantly increase the potential inhibition toward HDAC.
CBUD-1001 sensitively affects human CRC cell viability. To evaluate the biological effects of CBUD-1001, cell viability was examined following exposure to CBUD-1001 using human CRC cells and normal IECs. The cells were treated with various concentrations of CBUD-1001 (0.05, 0.1, 1, 10, 50,100 and $200 \mu \mathrm{M}$ ) for $24 \mathrm{~h}$. As revealed by the MTT assay, CBUD-1001 inhibited the growth of both the CRC cells and normal IECs in a concentration-dependent manner (Fig. 3). However, in calculating the $\mathrm{IC}_{50}$ value of CBUD-1001, it was 

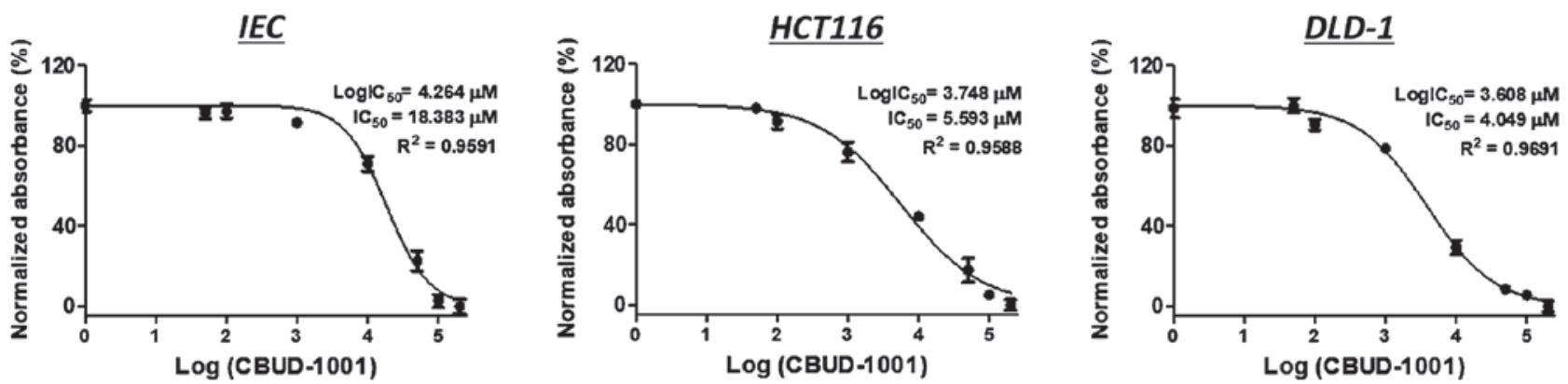

Figure 3. CBUD-1001 suppresses the viability of CRC cells. Human intestinal epithelial cells and CRC cells were treated with various concentration of CBUD-1001 for $24 \mathrm{~h}$ and cell viability was then measured by the mitochondrial MTT reduction activity assay. The $\mathrm{IC}_{50}$ values of CBUD-1001 were calculated using GraphPad Prism 5.0 software. CRC, colorectal cancer.

A

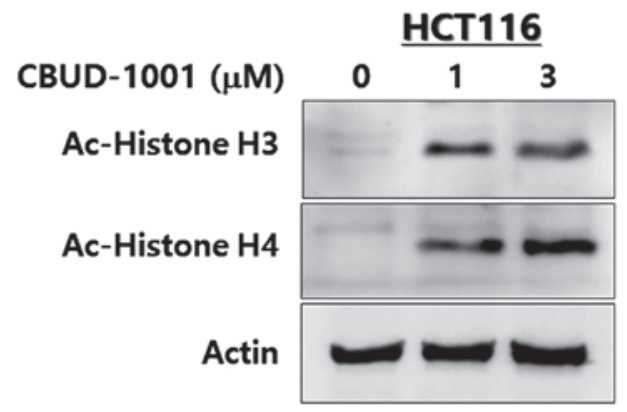

B

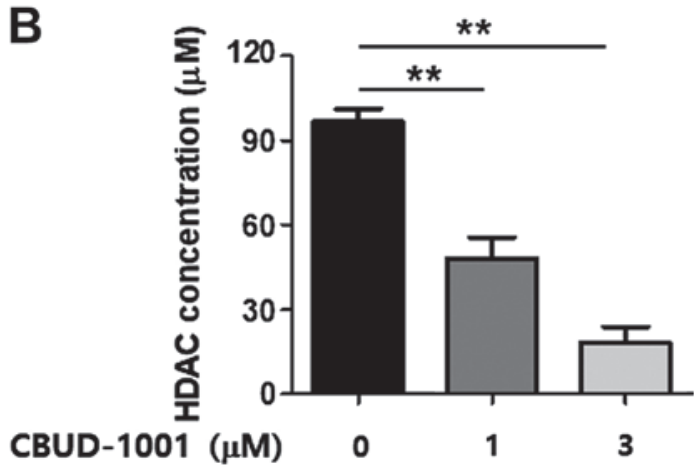

DLD-1
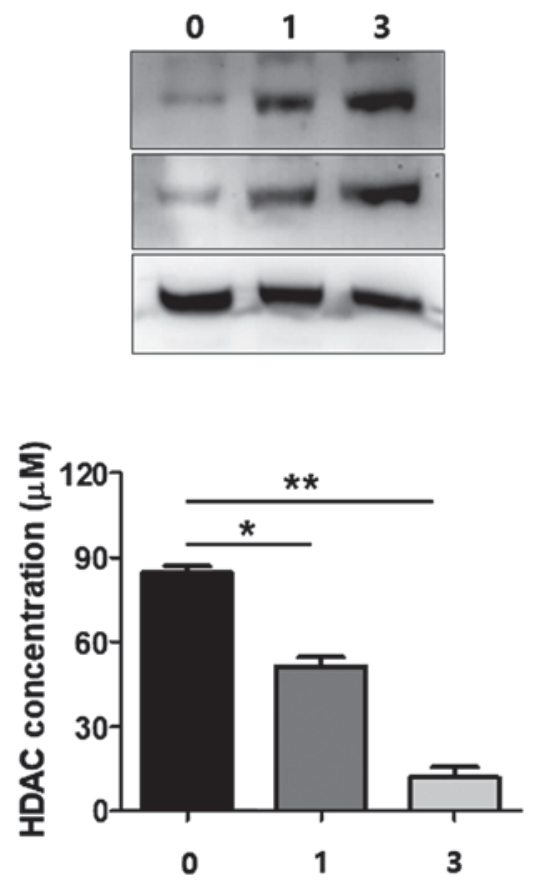

Figure 4. CBUD-1001 inhibits histone deacetylase (HDAC) activity in CRC cells. (A) CRC cells were treated with $0,1,3 \mu \mathrm{M}$ of CBUD-1001 for 24 h, total cell lysates were used for detection of acetyl-Histone $\mathrm{H} 3$ and $\mathrm{H} 4$ by western blot analysis. (B) Following treatment with CBUD-1001 for $24 \mathrm{~h}$, the inhibitory effect of total HDACs was assayed using a colorimetric HDAC activity assay kit. The HDAC concentration was calculated using the deacetylated standard. Histograms represent the means \pm SD from triplicate samples and are representative of 3 independent experiments. ${ }^{*} \mathrm{P}<0.01$ and ${ }^{* *} \mathrm{P}<0.05$. CRC, colorectal cancer.

confirmed that a higher concentration of CBUD-1001 was required for the IECs than for the CRC cells. The $\mathrm{IC}_{50}$ values of CBUD-1001 for $24 \mathrm{~h}$ in CRC cells viability were $5.593 \mu \mathrm{M}$ in the HCT116 cells and $4.049 \mu \mathrm{M}$ in the DLD-1 cells. For the positive control, the $\mathrm{IC}_{50}$ value of CBID-1001 in the human IECs was $18.383 \mu \mathrm{M}$. Thus, the CRC cells were more sensitive to CBUD-1001 than the normal IECs. However, the effect of CBUD-1001 on the long-term viability of CRC cells was not observed; thus, this is a limitation of the present study.

CBUD-1001 suppresses HDAC enzyme activity in CRC cells. As CBUD-1001 was designed to be an HDAC inhibitor, western blot analysis and a colorimetric HDAC activity assay with total cell lysates were used to evaluate its ability to inhibit HDACs. To confirm the ability of CBUD-1001 to inhibit the deacetylation of HDACs, western blot analysis was performed to analyze the acetylation of histones $\mathrm{H} 3$ and $\mathrm{H} 4$ in CRC cells. As was revealed by the results, $24 \mathrm{~h}$ of CBUD-1001 treatment dose-dependently increased the acetylation of histones $\mathrm{H} 3$ and H4 (Fig. 4A).

HDAC enzymatic activity also was evaluated using an HDAC activity assay kit, and the exact concentration of HDAC was calculated with a deacetylated standard (Ac-Lys-pNA 10-100 $\mu \mathrm{M})$. As shown in Fig. 4B, the dose-dependent inhibition of HDAC activity by CBUD-1001 was observed in the CRC cell lines. Thus, these results suggest that CBUD-1001 is a selective HDAC inhibitor that inactivates HDAC1 in human CRC cells.

CBUD-1001 triggers the apoptotic death of human CRC cells. As shown by the results presented in Figs. 3 and 4, it was confirmed that the HCT116 cells exhibited marked changes 
in cell viability and HDAC activity by CBUD-1001 treatment. Moreover, the HCT116 cells exhibited a spindle-like morphology, the typical characteristics of mesenchymal cells; thus, these cells can be more easily used for apoptosis and EMT-related analyses. For this reason, the HCT116 cells were selected as a representative CRC cell line for all the remaining in vitro experiments.

To verify whether CBUD-1001-induced cell death was caused by apoptosis, the apoptotic effect of CBUD-1001 was examined using various in vitro experiments. Hoechst 33258 staining was used to observe the apoptotic nuclear morphology to determine whether the cell death caused by CBUD-1001 in HCT116 cells was due to apoptosis. Following treatment with $1 \mu \mathrm{M}$ of CBUD-1001 for $24 \mathrm{~h}$, the HCT116 cells began to exhibit apoptotic characteristics, such as cell shrinkage, nuclear condensation and fragmentation. With $3 \mu \mathrm{M}$ of CBUD-1001, cell shrinkage was observed in the majority of the cells, and DNA fragments were found on the surface of the glass plate. In the control group, the cells continued to exhibit a regular in morphology, grew fully in patches, and were confluent, rarely sloughing off (Fig. 5A).

The rate of apoptotic cells was detected through a FACS analysis of Annexin V-FITC/PI staining (Fig. 5B). As was revealed by the results, the HCT116 cells treated with CBUD-1001 exhibited a higher rate of apoptotic cell death than the control cells. Moreover, apoptotic cell death was quantified by counting the cell populations in the lower right and upper right quadrants. The results revealed that the cell population in the $1 \mu \mathrm{M}$-treated group increased from $0.91 \pm 0.382$ to $11.28 \pm 1.134 \%$, and that in the $3 \mu \mathrm{M}$-treated group increased to $14.31 \pm 1.602 \%$.

Subsequently, it was further investigated whether CBUD-1001 affects the growth and survival of CRC cells in long-term culture. Following $24 \mathrm{~h}$ of treatment with the indicated concentrations of CBUD-1001, clones of the cells were cultured and then stained by crystal violet after 14 days. Compared with the control group, clonogenic growth assay revealed that the clonogenicity of the HCT116 cells was significantly decreased by CBUD-1001 in a dose-dependent manner (Fig. 5C). Taken together, these results indicate that CBUD-1001 potently suppresses the proliferation of human CRC cells.

CBUD-1001 activates the intrinsic apoptotic pathway. Mitochondrial dysfunction has been shown to participate in the early stages of apoptosis and has even been suggested to be central to the intrinsic apoptotic pathway (37). Thus, the $\Delta \psi \mathrm{m}$ was determined in the cells using Rhodamine 123 dye following $24 \mathrm{~h}$ of CBUD-1001 treatment (Fig. 6A). As was demonstrated, CBUD-1001 treatment triggered a significant loss of $\Delta \psi \mathrm{m}$ in the HCT116 cells; the ratio of the $\Delta \psi \mathrm{m}$ peak was $4.6 \pm 1.208 \%$ (control), $15.34 \pm 1.530 \%(1 \mu \mathrm{M})$ and $17.11 \pm 2.459 \%(3 \mu \mathrm{M})$.

To further investigate the mechanisms responsible for the apoptosis induced by CBUD-1001, western blot analysis was performed to detect the levels of apoptosis-related proteins in the HCT116 cells following $24 \mathrm{~h}$ of treatment (Fig. 6B). The results revealed that CBUD-1001 increased the cleavage of capase-8 (initiator of apoptosis) and Bid truncation (initiator of the intrinsic apoptotic pathway), whereas it decreased the expression of $\mathrm{Bcl}-2$ and $\mathrm{Bcl}-\mathrm{xL}$ (anti-apoptotic proteins). Moreover, the release of cytochrome $c$, accompanied by changes in the Bcl-2 family, was also detected in CBUD-1001-treated cells. Subsequently, whether CBUD-1001 regulates the protein levels of XIAP, which binds directly to caspases to prevent apoptosis, was examined. The results revealed that the level of XIAP was also decreased, and subsequent increases in caspase-3 activation was detected following CBUD-1001 treatment. The activation of caspase- 3 leads to the cleavage of their downstream molecular targets, including PARP, a terminal factor of apoptosis. As was shown by the results, the levels of cleaved PARP were increased by treatment with CBUD-1001. Collectively, these results suggest that the major mechanism of apoptosis induced by CBUD-1001 was the activation of the intrinsic apoptotic pathway.

CBUD-1001 suppresses cell motility by downregulating the $E M T$. During the in vitro experiments, it was observed that following treatment with CBUD-1001, the cell morphology altered and cells exhibited characteristics typically associated with EMT. As shown in Fig. 7A, the cells exhibited a less spindle-like morphology in the CBUD-1001-treated group than in the control group.

Subsequently, whether CBUD-1001 affects the motility of CRC cells was examined to verify its effect on the EMT process. Following $48 \mathrm{~h}$ of treatment with the indicated concentrations of CBUD-1001, the distance between the wound areas in HCT116 cells was markedly longer than in the control cells (Fig. 7B). The quantification of the wound area in the scratch tests revealed that the wound area in the control cells decreased by $35.87 \pm 6.33 \%$ after $48 \mathrm{~h}$, whereas following treatment with $3 \mu \mathrm{M}$ CBUD-1001, it increased by $88.94 \pm 10.30 \%$.

To elucidate the mechanismS of CBUD-1001 in EMT, the protein levels of EMT-associated markers in THE HCT116 cells were examined (Fig. 7C). First, the level of E-cadherin, a representative epithelial marker, was examined by western blot analysis. Following treatment with CBUD-1001, the E-cadherin level recovered in a dose-dependent manner. By contrast, the expression levels of mesenchymal markers, such as $\beta$-catenin, vimentin, MMP-2, MMP-9, SNAIL, and SLUG, decreased in a concentration-dependent manner, indicating that CBUD-1001 altered the morphological phenotype and suppressed cell motility by downregulating the EMT pathway.

\section{Discussion}

Over the past several decades, epigenetic alterations have been shown to be hallmarks of cancer (13). Histone acetylation, a well-studied epigenetic abnormality, is tightly controlled by a balance between the opposing activities of histone acetyltransferases and HDACs (38). Unusually, a high HDAC activity modulates gene expression through epigenetic mechanisms and leads to tumorigenesis. The elevated expression and activity of HDACs has been reported in several types of cancer, including CRC $(20,39)$. Recent studies have demonstrated that cancers are associated with abnormal cell functions, including apoptosis, cell motility and DNA repair. These cell functions are regulated at least in part by HDACs $(40,41)$. Therefore, HDACs have emerged as an important target in the development of 

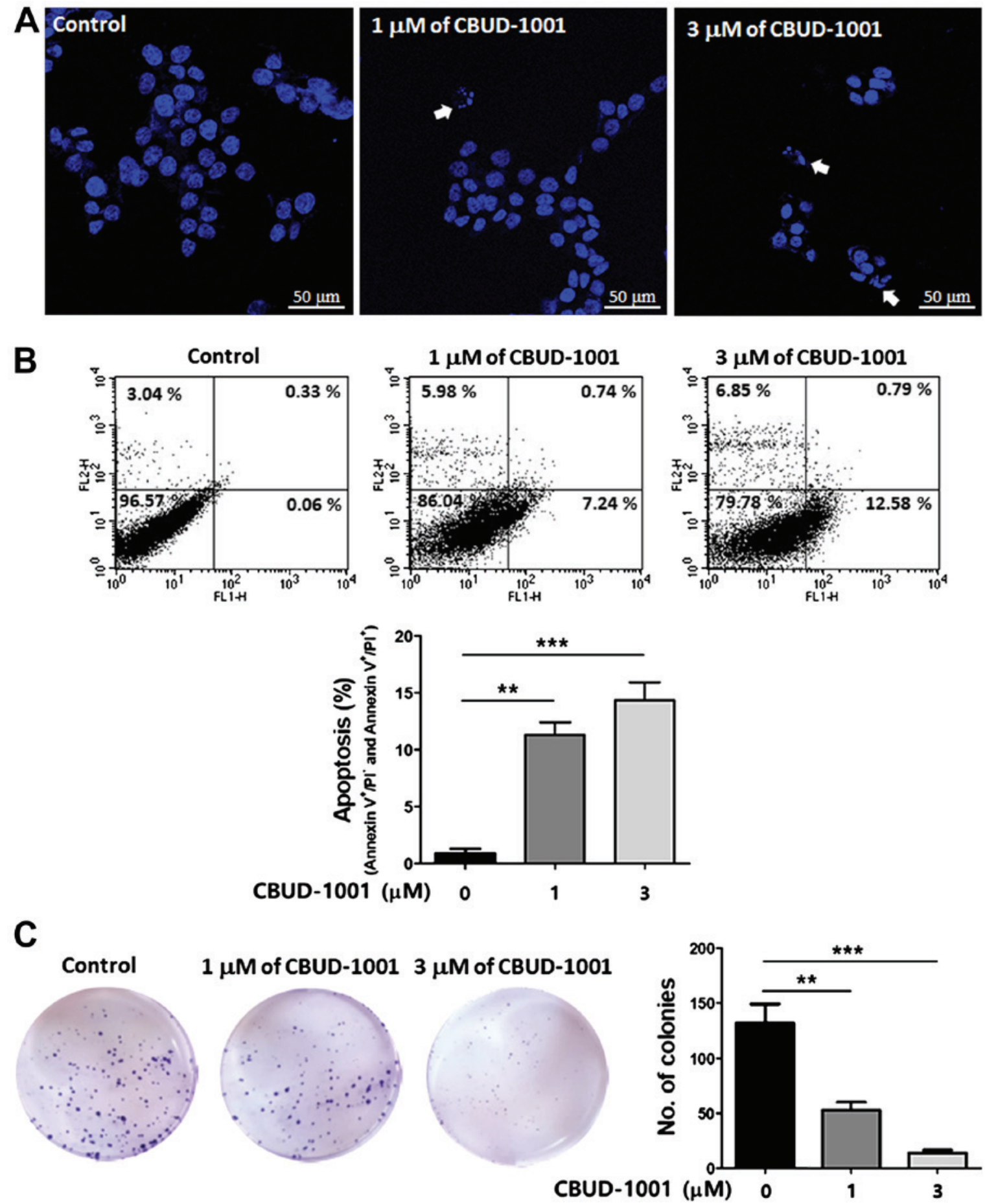

Figure 5. CBUD-1001 induces CRC cell apoptosis. (A) HCT116 cells were treated with the applied concentrations of CBUD-1001 for $24 \mathrm{~h}$, and the cells were then stained with Hoechst 33258 and observed using an a confocal laser scanning microscope. (B) Following treatment with CBUD-1001, the apoptosis in HCT116 cells were determined by flow cytometry following staining with Annxin V-FITC/PI. The percentages in each quadrant show the cell population of Annexin V (X-axis) and propidium iodide (Y-axis) staining cells. (C) HCT116 cells were seeded in a 6-well plate at a population of $1 \times 10^{2}$ cells/well, and were then treated with the indicated concentrations of CBUD-1001 for $24 \mathrm{~h}$. After 2 weeks, the cells were stained using crystal violet and images were captured. CRC, colorectal cancer. The histograms represent the means \pm SD from triplicate samples and are representative of 3 independent experiments. ${ }^{* *} \mathrm{P}<0.05$ and ${ }_{* * * *} \mathrm{P}<0.001$

anticancer agents, and a number of HDAC inhibitors have been developed (42). In the present study, the HDAC1-specific inhibitor, CBUD-1001, was developed and its potential utility to attenuate the tumorigenic properties of CRC cells was examined.

A previously reported study on benzamide-type HDAC inhibitors demonstrated that both the nitrogen of the ortho- $\mathrm{NH}_{2}$ group and the carbonyl group on the benzamide chelated with zinc. Moreover, this benzamide-type inhibitor selectively inhibited class I HDAC isoforms, which significantly reduced the side-effects of HDAC inhibition (43). Thus, the present study designed a novel fluorinated aminophenyl-benzamide based compound (CBUD-1001) as a potent HDAC inhibitor with high antitumor efficacy against CRC. 
A

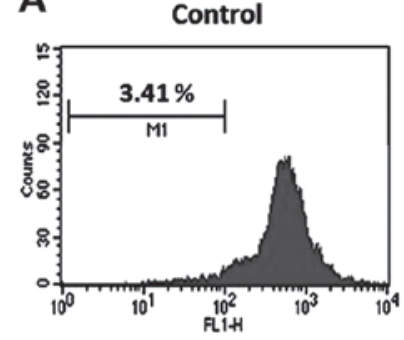

$1 \mu \mathrm{M}$ of CBUD-1001

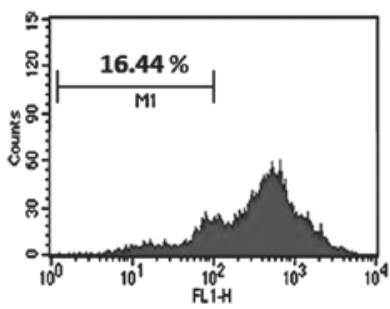

$3 \mu \mathrm{M}$ of CBUD-1001

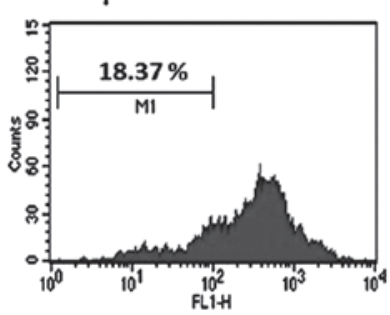

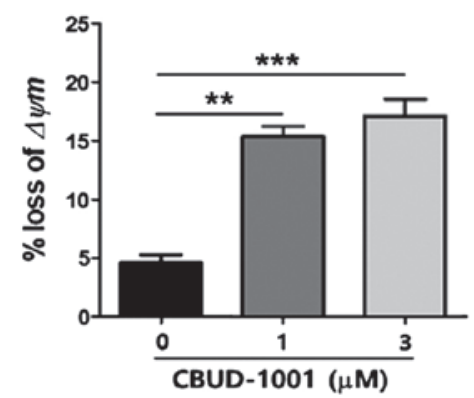

B
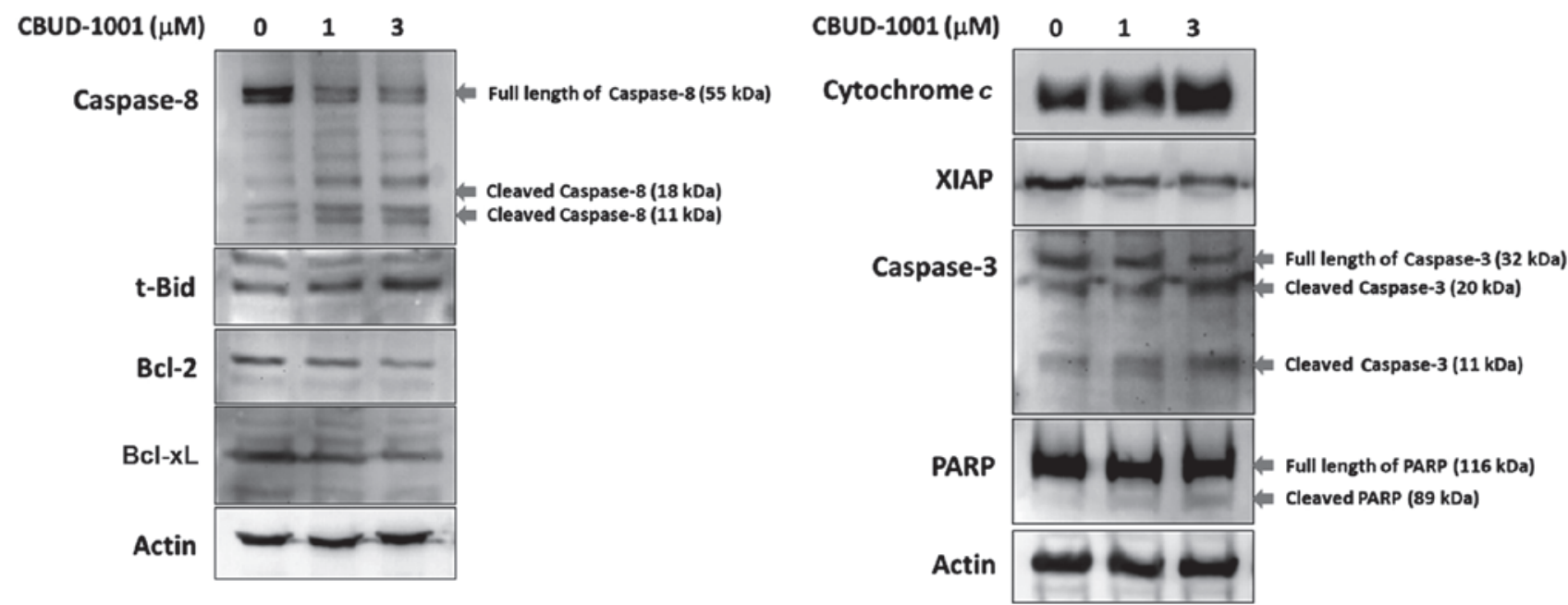

Figure 6. CBUD-1001 promotes apoptosis through the intrinsic pathway. (A) HCT116 cells were treated with the indicated concentrations of CBUD-1001 and then loaded with Rh-123 for 30 min. The inserted histogram demonstrates a left shift of histogram peak representing the decrease of Rh-123 fluorescence intensity due to the loss of $\Delta \psi \mathrm{m}$. Percentage of cells with reduced fluorescence intensity was calculated. The histograms represent the means \pm SD from triplicate samples and are representative of 3 independent experiments. ${ }^{* *} \mathrm{P}<0.05$ and ${ }^{* * *} \mathrm{P}<0.001$. (B) Following treatment of $\mathrm{CBUD}-1001$ for $24 \mathrm{~h}$, the levels of proteins belonging to intrinsic pathway were examined by western blot analysis.

The synthesis of the novel HDAC inhibitor (CBUD-1001) involved three parts. In the first part, the benzamide scaffold, which includes the zinc-binding and linker parts, was synthesized from 4-bromo-2-nitroaniline. Boc-protection, the Suzuki cross-coupling reaction, hydrogenation, amide bond formation, and Gabriel synthesis successfully provided 4-(aminomethyl) benzamide compounds with a $12 \%$ overall yield. In the second part, a fluorinated cyclic moiety was prepared as a cap group to attach the benzamide scaffold. 4-(Hydroxymethyl)cyclohexanecarboxylic acid was used as the starting material. The protection of the carboxylic acid group, tosylation, fluorination, and deprotection of the $\mathrm{Cbz}$ group were conducted to yield 4-(fluoromethyl)cyclohexanecarboxylic acid at a 50\% overall yield. In the final part of the synthesis, an EDC coupling reaction of 4-(aminomethyl)benzamide compound (the benzamide scaffold) and 4-(fluoromethyl)cyclohexanecarboxylic acid (the cap group) was followed by the deprotection of the Boc group to yield target compound (CBUD-1001) at a 56\% overall yield. The synthesis of CBUD-1001 used facile synthetic chemistry.

The efficacy of the newly prepared compound (CBUD-1001) against HDAC activity was then examined. The result of in vitro HDAC assay indicated that the novel CBUD-1001 possessed good inhibitory activity against HDAC1 and it also exhibited greater inhibitory activity against HDAC1 than SAHA, the non-specific HDAC inhibitor. In particular, its nanomolar inhibition suggested that the biaryl benzamide structure and fluorinated cyclic moiety were suitable for HDAC1 inhibition.

The general pharmacophore indicates that the structure of HDAC inhibitors includes 3 important components: The zinc binding group (ZBG) for chelating the zinc atom in the metalbinding site, the cap group for interacting with the external surface, and the linker for attaching the ZBG to the cap group and allowing the ZBG to access the active site $(5,32)$.

The nanomolar inhibition of CBUD-1001 indicated that the biaryl benzamide structure was compatible with the binding site of HDAC. A molecular docking analysis of the active HDAC sites was performed to investigate the binding mode of CBUD-1001. The results indicated that both the nitrogen of the ortho- $\mathrm{NH}_{2}$ group and the carbonyl group of CBUD-1001 could chelate with the Zn401 (Fig. 2). We observed an interaction between the ortho- $\mathrm{NH}_{2}$ group and His145, a hydrogen bond with $\mathrm{C}=\mathrm{O}$ on Gly154, and a $\pi-\pi$ stacking interaction of the phenyl group in the linker with Phe155. In addition, it was found that the thiophenyl group was suitably fitted, with a $14-\AA$-long internal cavity suggesting the enhancement of HDAC inhibition by CBUD-1001. Thus, the results of docking analysis rationalize the high inhibitory activity and potency of CBUD-1001 and suggest that CBUD-1001 may be a promising HDAC inhibitor with potential for use as an antitumor agent.

The class I HDACs (particularly HDAC1 and 2) are ubiquitously expressed and overexpressed in several tumor 

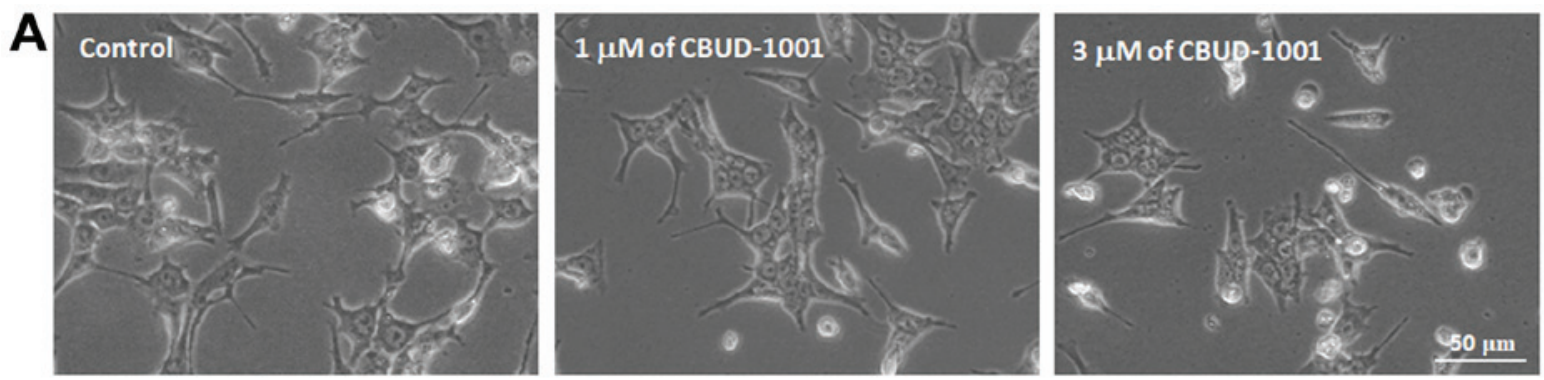

$\mathbf{O h}$

$48 \mathrm{~h}$
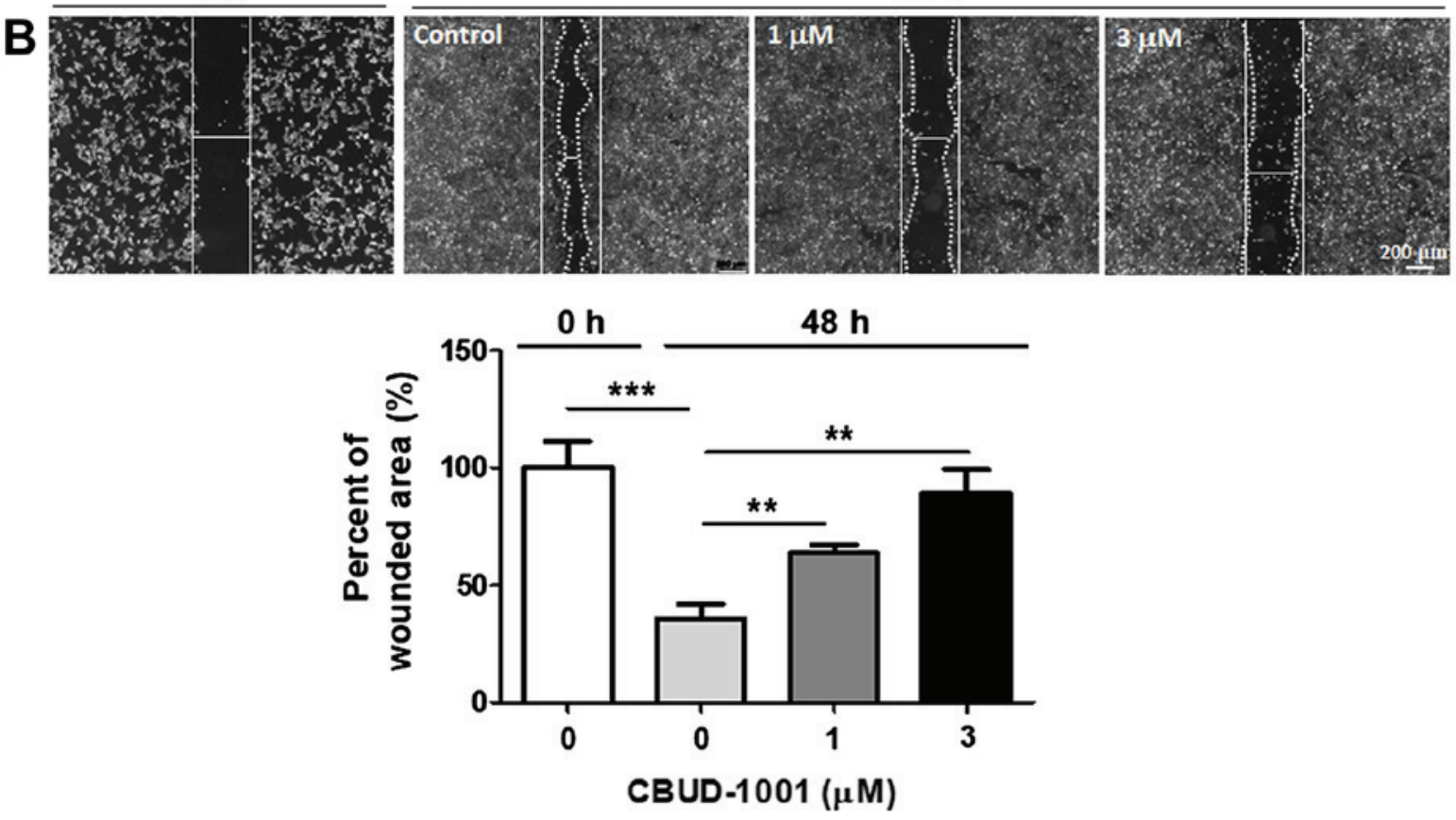

C

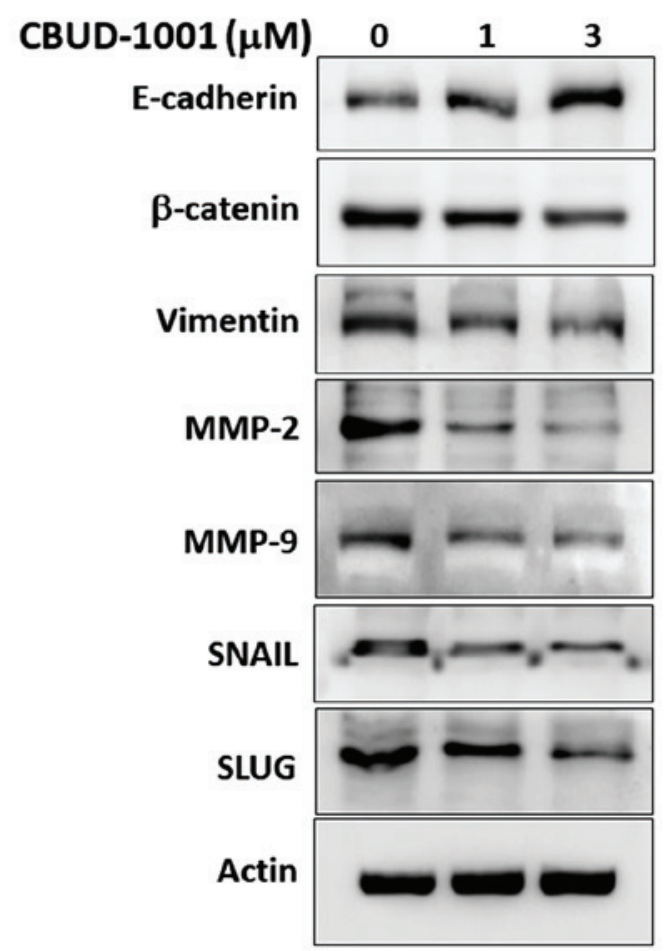

Figure 7. CBUD-1001 inhibits CRC cell motility through the EMT pathway. (A) Morphological changes of HCT116 cells treated with CBUD-1001 were captured using a phase contrast microscope. (B) Following treatment with CBUD-1001, HCT116 cells were scratched using a yellow tip and wound closure was evaluated at 0 and $48 \mathrm{~h}$. Quantitative measurements of wound closure ability are shown. The histograms represent the means \pm SD from triplicate samples and are representative of 3 independent experiments. ${ }^{* *} \mathrm{P}<0.05$ and ${ }^{* * * *} \mathrm{P}<0.001$. (C) Total cell lysates of HCT116 cells were prepared for western blot analysis. The protein levels of EMT markers were analyzed with the appropriate antibodies. Actin was used as a loading control. CRC, colorectal cancer. 
types, which renders them promising targets for HDAC inhibitor-mediated tumor therapy (5). The upregulation of HDAC1 has been observed in polyps and CRC compared with normal mucosa (44). Moreover, HDAC1 has been confirmed to be overexpressed in CRC by exploratory tissue-based expression analysis on small sets of tumors and to be significantly associated with CRC patient survival $(44,45)$. Important insights as to the functional effects of HDAC1 on the regulation of proliferation, apoptosis and tumorigenesis have been provided by in vitro and in vivo studies. In 2007, Senese et al reported that the silencing HDAC1 in osteosarcoma and breast cancer cells affected the transcription of specific target genes involved in proliferation and apoptosis (46). The knockdown of HDAC1 also caused a decrease in the proliferation of cervix adenocarcinoma cells (47). In CRC cells, Weichert et al demonstrated that the selective knockdown of $\mathrm{HDACl}$ using siRNA resulted in a significant reduction in the CX-2 cell population (45). Of note, another study demonstrated that the knockdown of HDAC1 produced the development of hematological malignancy, suggesting that HDAC1 has an ambiguous identity in the process of tumorigenesis (48). In the present study, the anticancer role of HDAC1 was examined by treating CRC cells with CBUD-1001. The results provide clear evidence that HDAC1 positively modulates CRC cell proliferation and survival.

HDAC inhibitors have been reported to activate either an extrinsic or intrinsic pathway in several types of cancer $(49,50)$. The mitochondrial apoptotic pathway (intrinsic pathway) is activated by stress stimuli (chemotherapeutic agents) and is regulated by the Bcl-2 family $(51,52)$. Biological events by $\mathrm{Bcl}-2$ family members in the apoptotic process can trigger mitochondrial dysfunction and the loss of $\Delta \Psi \mathrm{m}(53)$. Correspondingly, it was observed that CBUD-1001 induced the loss of $\Delta \Psi \mathrm{m}$ in CRC cells and regulated the protein level of Bcl-2 family members, suggesting that CBUD-1001 induced apoptosis via the intrinsic pathway. Following mitochondrial dysfunction, cytochrome $c$ in the mitochondrial membranes is released into the cytoplasm $(54,55)$. XIAP is considered to be the most potent apoptotic regulator in mammalian cells (56), and it inhibits caspase activity by binding directly to caspase-3, -7 and -9 in the apoptotic pathway (57). Downstream of cytochrome $c$, caspase- 3 is activated and leads to the cleavage of downstream molecular targets, including PARP, a hallmark of apoptosis (58). In the present study, the results of western blot analysis revealed a consistent alteration of apoptotic molecules, and these observations indicate that CBUD-1001 induces apoptosis via the intrinsic pathway by causing mitochondrial dysfunction in CRC cells.

EMT is a crucial process in cancer progression that provides cancer cells with the ability to escape from the primary site, invade stromal tissues and migrate to distant regions. As a result of EMT, epithelial cells lose their defined cellcell/cell-substratum contacts and their structural/functional polarity and become spindle shaped and morphologically similar to activated fibroblasts $(59,60)$. Recently, several studies reported that an HDAC inhibitor suppressed the EMT in various cells, including cancer cells. Sakamoto et al demonstrated that vorinostat (SAHA) suppressed the TGF- $\beta 1$-induced EMT and attenuated chemo-resistance in biliary tract cancer (61). A synergistic effect on the EMT from the use of silibinin and an HDAC inhibitor (trichostatin A) was also investigated in non-small cell lung cancer cells (62). Moreover, the suppressive effect of HDAC inhibitors on EMT in CRC was reported using valproic acid and trichostatin A $(24,63)$. In the present study, it was demonstrated that CBUD-1001 negatively regulated EMT in CRC cells, as shown through changes in cell morphology, motility and the expression level of various EMT markers (E-cadherin, $\beta$-catenin, Vimentin, MMP-2, MMP-9, SNAIL and SLUG). These observations suggest that CBUD-1001 may play a therapeutic role in $\mathrm{CRC}$ and its metastasis by inhibiting EMT. Taken together, the results indicate that CBUD-1001 has antitumor activity and may be a highly potent HDAC inhibitor for CRC cancer therapy. However, this requires further investigation, in order to fully elucidate the mechanisms through which CBUD-1001 regulates HDAC-mediated EMT signaling and metastasis using animal models.

In conclusion, even though several drugs are currently being used for CRC therapy, effective therapeutic agents are still needed. Several studies have suggested that HDAC inhibitors exhibit promise for cancer treatment (21-28). In the present study, a novel benzamide-based compound, CBUD-1001, that can inhibit HDACs was reported. Molecular docking analysis confirmed the high potency of CBUD-1001 as an HDAC1 inhibitor, and CBUD-1001 exhibited potent inhibitory activity against HDAC enzyme activity in CRC. Additionally, the results demonstrated that CBUD-1001 triggered the apoptotic death of human CRC cells, and suppressed cell motility by downregulating EMT. Therefore, the present results suggest that CBUD-1001 may be a novel potent therapeutic agent for CRC therapy.

\section{Acknowledgements}

Not applicable.

\section{Funding}

The present study was supported by the Fund of the Biomedical Research Institute, Jeonbuk National University Hospital and the CBNU fund overseas research 2007.

\section{Availability of data and materials}

All data generated or analyzed during this study are included in this published article or are available from the corresponding author on reasonable request.

\section{Authors' contributions}

HKK and SWK participated in the design of the study. HKK participated in the data analysis in the synthesis of the study and wrote the original draft. MTL synthesized, performed the docking analysis and wrote the original draft of the synthesis of the study. SLK and MWS carried out the molecular biology experiment. SLK wrote the draft of the molecular biology section and performed the statistical analysis. SWK edited the draft and supervised all experimental procedures. All authors have read and approved the final manuscript.

\section{Ethics approval and consent to participate}

Not applicable. 


\section{Patient consent for publication}

Not applicable.

\section{Competing interests}

The authors declare that they have no competing interests.

\section{References}

1. Ferlay J, Soerjomataram I, Dikshit R, Eser S, Mathers C, Rebelo M, Parkin DM, Forman D and Bray F: Cancer incidence and mortality worldwide: Sources, methods and major patterns in GLOBOCAN 2012. Int J Cancer 136: E359-E386, 2015.

2. Arnold M, Sierra MS, Laversanne M, Soerjomataram I, Jemal A and Bray F: Global patterns and trends in colorectal cancer incidence and mortality. Gut 66: 683-691, 2017.

3. Haggar FA and Boushey RP: Colorectal cancer epidemiology: Incidence, mortality, survival, and risk factors. Clin Colon Rectal Surg 22: 191-197, 2009

4. Lao VV and Grady WM: Epigenetics and colorectal cancer. Nat Rev Gastroenterol Hepatol 8: 686-700, 2011.

5. Bertrand P: Inside HDAC with HDAC inhibitors. Eur J Med Chem 45: 2095-2116, 2010.

6. Jackson MD and Denu JM: Structural identification of 2'- and 3'-O-acetyl-ADP-ribose as novel metabolites derived from the Sir2 family of beta-NAD+-dependent histone/protein deacetylases. J Biol Chem 277: 18535-18544, 2002.

7. Lombardi PM, Cole KE, Dowling DP and Christianson DW: Structure, mechanism, and inhibition of histone deacetylases and related metalloenzymes. Curr Opin Struct Biol 21: 735-743, 2011.

8. Haberland M, Montgomery RL and Olson EN: The many roles of histone deacetylases in development and physiology: Implications for disease and therapy. Nat Rev Genet 10: 32-42, 2009.

9. Kelly RD and Cowley SM: The physiological roles of histone deacetylase (HDAC) 1 and 2: Complex co-stars with multiple leading parts. Biochem Soc Trans 41: 741-749, 2013.

10. Lagger G, Doetzlhofer A, Schuettengruber B, Haidweger E, Simboeck E, Tischler J, Chiocca S, Suske G, Rotheneder H, Wintersberger E and Seiser C: The tumor suppressor p53 and histone deacetylase 1 are antagonistic regulators of the cyclin-dependent kinase inhibitor p21/WAF1/CIP1 gene. Mol Cell Biol 23: 2669-2679, 2003.

11. Ropero S and Esteller M: The role of histone deacetylases (HDACs) in human cancer. Mol Oncol 1: 19-25, 2007, 2007.

12. Hill R, Bodzak E, Blough MD and Lee PW: p53 Binding to the p21 promoter is dependent on the nature of DNA damage. Cel Cycle 7: 2535-2543, 2008.

13. Li Y and Seto E: HDACs and HDAC inhibitors in cancer development and therapy. Cold Spring Harb Perspect Med 6: a026831, 2016.

14. Zhu P, Martin E, Mengwasser J, Schlag P, Janssen KP and Göttlicher M: Induction of HDAC2 expression upon loss of APC in colorectal tumorigenesis. Cancer Cell 5: 455-463, 2004.

15. Stypula-Cyrus Y, Damania D, Kunte DP, Cruz MD, Subramanian H, Roy HK and Backman V: HDAC up-regulation in early colon field carcinogenesis is involved in cell tumorigenicity through regulation of chromatin structure. PLoS One 8: e64600, 2013.

16. Spaderna S, Schmalhofer O, Hlubek F, Berx G, Eger A, Merkel S, Jung A, Kirchner T and Brabletz T: A transient, EMT-linked loss of basement membranes indicates metastasis and poor survival in colorectal cancer. Gastroenterology 131: 830-840, 2006.

17. Barrallo-Gimeno A and Nieto MA: The Snail genes as inducers of cell movement and survival: Implications in development and cancer. Development 132: 3151-3161, 2005.

18. Peinado H, Ballestar E, Esteller M and Cano A: Snail mediates E-cadherin repression by the recruitment of the Sin3A/histone deacetylase 1 (HDAC1)/HDAC2 complex. Mol Cell Biol 24 306-319, 2004.

19. Jurkin J,Zupkovitz G, Lagger S, Grausenburger R, Hagelkruys A, Kenner L and Seiser C: Distinct and redundant functions of histone deacetylases HDAC1 and HDAC2 in proliferation and tumorigenesis. Cell Cycle 10: 406-412, 2011.

20. Mariadason JM: HDACs and HDAC inhibitors in colon cancer. Epigenetics 3: 28-37, 2008.
21. Sun PC, Tzao C, Chen BH, Liu CW, Yu CP and Jin JS Suberoylanilide hydroxamic acid induces apoptosis and sub-G1 arrest of 320 HSR colon cancer cells. J Biomed Sci 17: 76, 2010.

22. Wang TY, Jia YL, Zhang X, Sun QL, Li YC, Zhang JH, Zhao CP, Wang XY and Wang L: Treating colon cancer cells with FK228 reveals a link between histone lysine acetylation and extensive changes in the cellular proteome. Sci Rep 5: 18443, 2015.

23. Zhijun H, Shusheng W, Han M, Jianping L, Li-Sen Q and Dechun L: Pre-clinical characterization of 4SC-202, a nove class I HDAC inhibitor, against colorectal cancer cells. Tumour Biol 37: 10257-10267, 2016.

24. Ji M, Lee EJ, Kim KB, Kim Y, Sung R, Lee SJ, Kim DS and Park SM: HDAC inhibitors induce epithelial-mesenchymal transition in colon carcinoma cells. Oncol Rep 33: 2299-2308, 2015.

25. Patel MM and Patel BM: Repurposing of sodium valproate in colon cancer associated with diabetes mellitus: Role of HDAC inhibition. Eur J Pharm Sci 121: 188-199, 2018.

26. Bracker TU, Sommer A, Fichtner I, Faus H, Haendler B and Hess-Stumpp H: Efficacy of MS-275, a selective inhibitor of class I histone deacetylases, in human colon cancer models. Int J Oncol 35: 909-920, 2009.

27. Jin JS, Tsao TY, Sun PC, Yu CP and Tzao C: SAHA inhibits the growth of colon tumors by decreasing histone deacetylase and the expression of cyclin D1 and survivin. Pathol Oncol Res 18: 713-7120, 2012.

28. Chou CW, Wu MS, Huang WC and Chen CC: HDAC inhibition decreases the expression of EGFR in colorectal cancer cells. PLoS One 6: e18087, 2011.

29. Khan N, Jeffers M, Kumar S, Hackett C, Boldog F, Khramtsov N, Qian X, Mills E, Berghs SC, Carey N, et al: Determination of the class and isoform selectivity of small-molecule histone deacetylase inhibitors. Biochem J 409: 581-589, 2008.

30. Kelly WK, O'Connor OA, Krug LM, Chiao JH, Heaney M, Curley T, MacGregore-Cortelli B, Tong W, Secrist JP, Schwartz L, et al: Phase I study of an oral histone deacetylase inhibitor, suberoylanilide hydroxamic acid, in patients with advanced cancer. J Clin Oncol 23: 3923-3931, 2005.

31. Flis S, Gnyszka A, Flis K and Spławiński J: MS275 enhances cytotoxicity induced by 5 -fluorouracil in the colorectal cancer cells. Eur J Pharmacol 627: 26-32, 2010.

32. Zhang L, Zhang J, Jiang Q, Zhang L and Song W: Zinc binding groups for histone deacetylase inhibitors. J Enzyme Inhib Med Chem 33: 714-721, 2018

33. Lu H, Chen YD, Yang B and You QD: Design, synthesis and biological evaluation of novel histone deacetylase inhibitors based on virtual screening. Acta Pharmaceutica Sinica B 1: 240-247, 2011.

34. Vaisburg A, Paquin I, Bernstein N, Frechette S, Gaudette F, Leit S, Moradei O, Raeppel S, Zhou N, Bouchain G, et al: N-(2-Amino-phenyl)-4-(heteroarylmethyl)-benzamides as new histone deacetylase inhibitors. Bioorg Med Chem Lett 17: 6729-6733, 2007.

35. Methot JL, Chakravarty PK, Chenard M, Close J, Cruz JC, Dahlberg WK, Fleming J, Hamblett CL, Hamill JE, Harrington P, et al: Exploration of the internal cavity of histone deacetylase (HDAC) with selective HDAC1/HDAC2 inhibitors (SHI-1: 2). Bioorg Med Chem Lett 18: 973-978, 2008.

36. Lauffer BEL, Mintzer R, Fong RN, Mukund S, Tam C, Zilberleyb I, Flicke B, Ritscher A, Fedorowicz G, Vallero R, et al: Histone deacetylase (HDAC) inhibitor kinetic rate constants correlate with cellular histone acetylation but not transcription and cell viability. J Biol Chem 288: 26926-26943, 2013.

37. Zamzami N, Marchetti P, Castedo M, Zanin C, V Vayssière JL, Petit PX and Kroemer G: Reduction in mitochondrial potential constitutes an early irreversible step of programmed lymphocyte death in vivo. J Exp Med 181: 1661-1672, 1995.

38. Seto E and Yoshida M: Erasers of histone acetylation: The histone deacetylase enzymes. Cold Spring Harb Perspect Biol 6: a018713, 2014

39. Spurling CC, Godman CA, Noonan EJ, Rasmussen TP, Rosenberg DW and Giardina C: HDAC3 overexpression and colon cancer cell proliferation and differentiation. Mol Carcinog 47: 137-147, 2008.

40. Chen HP, Zhao YT and Zhao TC: Histone deacetylases and mechanisms of regulation of gene expression. Crit Rev Oncog 20: $35-47,2015$

41. Audia JE and Campbell RM: Histone modifications and cancer. Cold Spring Harb Perspect Biol 8: a019521, 2016.

42. De Souza C and Chatterji BP. HDAC inhibitors as novel anti-cancer therapeutics. Recent Pat Anticancer Drug Discov 10: $145-162,2015$. 
43. Bozorgi AH, Bagheri M, Aslebagh R and Rajabi MS: A structure-activity relationship survey of histone deacetylase (HDAC) inhibitors. Chemometr Intell Lab 125: 132-138, 2013.

44. Huang BH, Laban M, Leung CH, Lee L, Lee CK, Salto-Tellez M, Raju GC and Hooi SC: Inhibition of histone deacetylase 2 increases apoptosis and p21Cip1/WAF1 expression, independent of histone deacetylase 1. Cell Death Differ 12: 395-404, 2005.

45. Weichert W, Roske A, Niesporek S, Noske A, Buckendahl AC, Dietel M, Gekeler V, Boehm M, Beckers T and Denkert C: Class I histone deacetylase expression has independent prognostic impact in human colorectal cancer: Specific role of class I histone deacetylases in vitro and in vivo. Clin Cancer Res 14: $1669-1677,2008$

46. Senese S, Zaragoza K, Minardi S, Muradore I, Ronzoni S, Passafaro A, Bernard L, Draetta GF, Alcalay M, Seiser C and Chiocca S: Role for histone deacetylase 1 in human tumor cell proliferation. Mol Cell Biol 27: 4784-4795, 2007.

47. Glaser KB, Li J, Staver MJ, Wei RQ, Albert DH and Davidsen SK: Role of class I and class II histone deacetylases in carcinoma cells using siRNA. Biochem Biophys Res Commun 310: 529-536, 2003.

48. SantoroF, Botrugno OA, Dal Zuffo R, Pallavicini I, Matthews GM, Cluse L, Barozzi I, Senese S, Fornasari L, Moretti S, et al: A dual role for Hdac1: Oncosuppressor in tumorigenesis, oncogene in tumor maintenance. Blood 121: 3459-3468, 2013.

49. Huang L, Sowa Y, Sakai T and Pardee AB: Activation of the p21WAF1/CIP1 promoter independent of p53 by the histone deacetylase inhibitor suberoylanilide hydroxamic acid (SAHA) through the Sp1 sites. Oncogene 19: 5712-5719, 2000.

50. Rikiishi H: Autophagic and apoptotic effects of HDAC inhibitors on cancer cells. J Biomed Biotechnol 2011: 830260, 2011.

51. Green DR and Reed JC: Mitochondria and apoptosis. Science 281: 1309-1312, 1998

52. Yang E and Korsmeyer SJ: Molecular thanatopsis: A discourse on the BCL2 family and cell death. Blood 88: 386-401, 1996.
53. Kroemer G and Reed JC: Mitochondrial control of cell death. Nat Med 6: 513-519, 2000.

54. Adams JM and Cory S: The Bcl-2 protein family: Arbiters of cell survival. Science 281: 1322-1326, 1998.

55. Gross A, McDonnell JM and Korsmeyer SJ: BCL-2 family members and the mitochondria in apoptosis. Genes Dev 13: 1899-1911, 1999.

56. Lencz T, Guha S, Liu C, Rosenfeld J, Mukherjee S, DeRosse P, John M, Cheng L, Zhang C, Badner JA, et al: Genome-wide association study implicates NDST3 in schizophrenia and bipolar disorder. Nat Commun 4: 2739, 2013.

57. Eckelman BP, Salvesen GS and Scott FL: Human inhibitor of apoptosis proteins: Why XIAP is the black sheep of the family. EMBO Rep 7: 988-994, 2006.

58. Grutter MG: Caspases: Key players in programmed cell death. Curr Opin Struct Biol 10: 649-655, 2000.

59. Lee JM, Dedhar S, Kalluri R and Thompson EW: The epithelial-mesenchymal transition: New insights in signaling, development, and disease. J Cell Biol 172: 973-981, 2006.

60. Zhang Y and Weinberg RA: Epithelial-to-mesenchymal transition in cancer: Complexity and opportunities. Front Med 12: 361-373, 2018

61. Sakamoto T, Kobayashi S, Yamada D, Nagano H, Tomokuni A, Tomimaru Y, Noda T, Gotoh K, Asaoka T, Wada H, et al: A Histone deacetylase inhibitor suppresses epithelial-mesenchymal transition and attenuates chemoresistance in biliary tract cancer. PLoS One 11: e0145985, 2016.

62. Mateen S, Raina K, Agarwal C, Chan D and Agarwal R: Silibinin synergizes with histone deacetylase and DNA methyltransferase inhibitors in upregulating E-cadherin expression together with inhibition of migration and invasion of human non-small cell lung cancer cells. J Pharmacol Exp Ther 345: 206-214, 2013.

63. Feng J, Cen J, Li J, Zhao R, Zhu C, Wang Z, Xie J and Tang W: Histone deacetylase inhibitor valproic acid (VPA) promotes the epithelial mesenchymal transition of colorectal cancer cells via up regulation of Snail. Cell Adh Migr 9: 495-501, 2015. 